\title{
The Roles of Epinephelus coioides miR-122 in SGIV Infection and Replication
}

\author{
Hong-Yan Sun ${ }^{1} \cdot$ Yu-Ling Su ${ }^{1}$. Pin-Hong $\mathrm{Li}^{1}$ • Jia-Yang He ${ }^{1} \cdot$ He-Jia Chen ${ }^{1} \cdot$ Gang Wang ${ }^{1}$. Shao-Wen Wang ${ }^{1}$. \\ Xiao-Hong Huang ${ }^{1} \cdot$ You-Hua Huang ${ }^{1} \cdot$ Qi-Wei Qin ${ }^{1}$
}

Received: 22 August 2020 / Accepted: 18 January 2021 / Published online: 11 February 2021

(c) The Author(s) 2021

\begin{abstract}
In mammals, mature miR-122 is 22 nucleotides long and can be involved in regulating a variety of physiological and biological pathways. In this study, the expression profile and effects of grouper Epinephelus coioides miR-122 response to Singapore grouper iridovirus (SGIV) infection were investigated. The sequences of mature microRNAs (miRNAs) from different organisms are highly conserved, and miR-122 from E. coioides exhibits high similarity to that from mammals and other fish. The expression of miR-122 was up-regulated during SGIV infection. Up-regulation of miR-122 could significantly enhance the cytopathic effects (CPE) induced by SGIV, the transcription levels of viral genes (MCP, VP19, LITAF and ICP18), and viral replication; reduce the expression of inflammatory factors (TNF-a, IL-6, and IL-8), and the activity of AP-1 and NF- $\mathrm{KB}$, and miR-122 can bind the target gene p38 $\alpha$ MAPK to regulate the SGIV-induced cell apoptosis and the protease activity of caspase-3. The results indicated that SGIV infection can up-regulate the expression of E. coioides miR-122, and up-regulation of miR-122 can affect the activation of inflammatory factors, the activity of AP-1 and NF- $\mathrm{KB}$, and cell apoptosis to regulate viral replication and proliferation.
\end{abstract}

Keywords Epinephelus coioides $\cdot \mathrm{miR}-122 \cdot \mathrm{SGIV} \cdot$ Apoptosis

\section{Introduction}

MicroRNAs (miRNAs), approximately $18-25$ bp nucleotides, are small non-coding RNAs that participate in gene transcription and expression by regulating the target genes (Pillai et al. 2007; Sticht et al. 2018; Yurikova et al. 2019; Jangra et al. 2010). They were first discovered in Caenorhabditis elegans in 1990 and have quickly been recognized as fundamental components of systems that

Hong-Yan Sun and Yu-Ling Su contributed equally to this study.

You-Hua Huang

huangyh@scau.edu.cn

Qi-Wei Qin

qinqw@scau.edu.cn

1 Joint Laboratory of Guangdong Province and Hong Kong Regions on Marine Bioresource Conservation and Exploitation, Guangdong Laboratory for Lingnan Modern Agriculture, College of Marine Sciences, South China Agricultural University, Guangdong Province 510642 Guangzhou, People's Republic of China regulate gene expression (Lee et al. 1993). Today, miRNAs have been shown to be widespread in metazoans, plants, invertebrates, and vertebrates and can modulate many fundamental biological processes, such as cell growth, proliferation, differentiation, immuno-inflammatory responses, and apoptosis (Bushati and Cohen 2007; Bartel 2004).

MiR-122, a 22-nucleotide miRNA, was first discovered in the liver of adult mice (Lagos-Ouintana et al. 2002). Subsequently, the roles of miR-122 were elucidated. In mammals, miR-122 is one of the most abundant miRNAs in the liver, and it is also expressed in other tissues (Li et al. 2015; Laudadio et al. 2012; Xu et al. 2010; Bandiera et al. 2015; Fong et al. 2015). MiR-122 can regulate different pathways to participate in the following functions: regulating p53/Akt signaling, miR122 can be involved in chemotherapy-induced apoptosis in cutaneous $\mathrm{T}$ cell lymphoma (Manfe et al. 2012); regulating the Hsp-70-dependent NF- $\mathrm{KB}$ pathway by targeting FOXO3, it can inhibit ischemic neuronal death (Guo et al. 2018); inhibiting the TLR4/MyD88/NF- $\kappa B$ p65 signaling pathway, it can reduce lipid accumulation and inflammation in LO2 cells induced by $\mathrm{OA}(\mathrm{Hu}$ et al. 
2019); targeting IGF1R and regulating the PI3K/Akt/ $\mathrm{mTOR} / \mathrm{p} 70 \mathrm{~S} 6 \mathrm{~K}$ pathway, it can inhibit tumors such as breast cancer cell proliferation and tumorigenesis (Wang et al. 2012). MiR-122 can be involved in regulating the viral infection: it is essential for the production of hepatitis C virus (HCV) infection (Jangra et al. 2010); it can reduce the replication of Hepatitis B virus (HBV), indicating that miR-122 may represent a potential therapy for treatment of HBV infection (Song et al. 2015); it can repress the translation and replication of Borna disease virus (BDV) and the espression of IFN $\alpha$ and IFN $\beta$ to regulate the interaction between virus and host (Qian et al. 2010).

In recent years, the roles of miR-122 in lower vertebrates, such as fish, have been subsequently explored. In Danio rerio, anti-miR-122 can suppress zebrafish liver development (Laudadio et al. 2012); in Oreochromis niloticus, miR-122 can promote genetically modified farmed tilapia by directly targeting metallothionein genes to prevent the oxidative defense of the liver against cadmium (Qiang et al. 2017), and in Oncorhynchus mykiss, miRNA-122b promotes the expression of lipogenic genes and inhibits the expression of lipolytic genes (Mennigen et al. 2012, 2014). However, few reports have focused on the role miR-122 in fish during viral infection.

Grouper Epinephelus coioides is an economically important maricultured fish in China and Southeast Asian counties. Singapore grouper iridovirus (SGIV), a large cytoplasmic DNA virus, can cause high mortality rates in groupers and substantial economic losses to the aquaculture industry (Song et al. 2004). Only one type of miR-122 was found in E. coioides, and the miR-122 sequence of E. coioides was as that of miR-122a. In this study, the expression profile of E. coioides miR122 during SGIV infection, and its roles in AP-1 and $\mathrm{NF}-\kappa \mathrm{B}$ activation, and SGIV-induced cell apoptosis were investigated.

\section{Materials and Methods}

\section{Cell and Virus}

Grouper spleen (GS) cells and fathead minnow (FHM) cells were propagated in our laboratory with Leibovitz's L-15 medium containing $10 \%$ fetal bovine serum (Gibco, USA) at $28{ }^{\circ} \mathrm{C}$. The SGIV used in this study was originally separated and propagated by our laboratory as previously described (Qin et al. 2002). Virus-infected cells were collected and stored at $-80{ }^{\circ} \mathrm{C}$ for further analysis. Virus was titrated by the $50 \%$ tissue culture infectious dose $\left(\mathrm{TCID}_{50}\right)$ assay, and an m.o.i. of 0.1 was used for the experiments (Ni et al. 2017).

\section{MiR-122 and Plasmid Transfection}

MiR-122 mimics (miR-122) and control mimics (miRcon) were from RiboBio (RiboBio, China). MiR-122 or miR-con $(100 \mathrm{nM})$ was transfected into FHM/GS cells by Lipofectamine RNAiMAX (Invitrogen, USA) according to the manufacturer's instructions. The plasmid was transfected by Lipofectamine 2000 (Invitrogen) as previously described (Ni et al. 2017).

\section{RNA Extraction and cDNA Synthesis}

Total RNA was extracted by TRIzol reagent (Invitrogen, USA). ReverTra Ace kit (TOYOBO, Japan) was used to prepare cDNA according to the manufacturer's instructions. MiR-122 bulge-loop reverse transcription was performed with a specific customized miRNA RT kit (RiboBio, China). RNA $(1.5 \mu \mathrm{g})$ was denatured at $70{ }^{\circ} \mathrm{C}$ for $10 \mathrm{~min}$. Twenty microliter reaction contains $4 \mu \mathrm{l}$ of $5 \times$ RT buffer, 5 pmol miR-122 bulge-loop RT primers, $1 \mu \mathrm{l}$ of RT polymerase, and $1.5 \mu \mathrm{g}$ RNA. The reaction was performed inreverse transcription system: $42{ }^{\circ} \mathrm{C}, 60 \mathrm{~min} ; 72{ }^{\circ} \mathrm{C}, 10 \mathrm{~min}$.

\section{Real-Time Quantitative PCR}

miR-122 level was determined by real-time quantitative PCR (qPCR) using a bulge-loop qPCR starter kit (RiboBio, China) and performed on Q5 detection system (Thermo, USA). A $10 \mu \mathrm{l}$ reaction contained $5 \mu \mathrm{l} \mathrm{SYBR}$ qPCR mix, $0.4 \mu$ l forward and reverse bulge-loop miRNA primers (miR-122, U6, and $\beta$-actin primers were provided

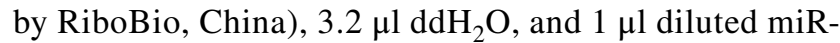
122 specific cDNA. The PCR program was $95^{\circ} \mathrm{C}, 1 \mathrm{~min}$; $\left(95{ }^{\circ} \mathrm{C}, 15 \mathrm{~s} ; 60^{\circ} \mathrm{C}, 30 \mathrm{~s}\right)$ for 40 cycles. Small nuclear RNA U6 and $\beta$-actin were used as a reference in this study (Liu et al. 2012). Host genes and viral genes were determined by qPCR. A $10 \mu 1$ reaction containing $5 \mu 1$ SYBR qPCR mix, $0.4 \mu 1$ forward and reverse primers (Table 1), $3.2 \mu 1 \mathrm{ddH}_{2} \mathrm{O}$, and $1 \mu 1$ diluted cDNA was performed in the PCR program: $95^{\circ} \mathrm{C}, 1 \min \left(95^{\circ} \mathrm{C}\right.$, $15 \mathrm{~s} ; 60{ }^{\circ} \mathrm{C}, 15 \mathrm{~s} ; 72{ }^{\circ} \mathrm{C}, 45 \mathrm{~s}$ ) for 45 cycles. $\beta$-Actin and $18 \mathrm{~S}$ rDNA were used as a reference, respectively (Guo et al. 2016; Huang et al. 2016a, b; Su et al. 2019). PCR amplification was performed in quadruplicate wells. The expression of the genes was calculated with the $2^{-\Delta \Delta \mathrm{Ct}}$ method (Su et al. 2019). 
Table 1 Primers used in this study

\begin{tabular}{|c|c|}
\hline Primer & Sequence ( $5^{\prime}$ to $\left.3^{\prime}\right)$ \\
\hline TNF $\alpha-F$ & GTGTCCTGCTGTTTGCTTGGTA \\
\hline TNF $\alpha-R$ & CAGTGTCCGACTTGATTAGTGCTT \\
\hline IL-6-F & CTCTACACTCAACGCGTACATGC \\
\hline IL-6-R & TCATCTTCAAACTGCTTTTCGTG \\
\hline IL-8-F & GCCGTCAGTGAAGGGAGTCTAG \\
\hline IL-8-R & ATCGCAGTGGGAGTTTGCA \\
\hline Bax-F & TGTGCGACCCAAATACCAAGAGG \\
\hline Bax-R & AAGTAGAACAGTGCAACCACCCTGC \\
\hline p53-F & GGAGGAAAACAGCACCAAGACGC \\
\hline $\mathrm{p} 53-\mathrm{R}$ & CCACGAACATGCAGAACAAACACG \\
\hline$\beta$-actin-F & TGCTGTCCCTGTATGCCTCT \\
\hline$\beta$-actin-R & CCTTGATGTCACGCACGAT \\
\hline 18S-qRT-F & ATTGACGGAAGGGCACCACCAG \\
\hline 18S-qRT-R & TCGCTCCACCAACTAAGAACGG \\
\hline$\beta$-actin-F & TGCTGTCCCTGTATGCCTCT \\
\hline$\beta$-actin-R & CCTTGATGTCACGCACGAT \\
\hline p38 $\alpha$-UTR-F1 & GACTAGTTGAGTTTTGAGCCACCGTCGTT \\
\hline p38 $\alpha$-UTR-R1 & CAAGCTTCGGCAGGCACTTGAATGTC \\
\hline p38 $\alpha$-mUTR3-F1 & CCAGGAATGTGAGGTTAAAGACTATCAGTCTCTTGT \\
\hline p38 $\alpha$-mUTR3-R1 & СТTТАAССТСАСАТTССТGGAAAACAAAAAGAT \\
\hline
\end{tabular}

\section{The Prediction of Target Genes}

3' untranslated region (UTR) regions of E. coioides immunerelated genes from NCBI database and the E. coioides ESTs sequence database in our laboratory were analyzed. RNAhybrid (https://bibiserv.cebitec.uni-bielefeld.de/rnahy brid) was used to predict the potential targets of miR-122 and energy threshold was set at less than or equal to $-15 \mathrm{kcal} / \mathrm{mol}$.

\section{Construction of Target-Contained Luciferase Plasmids}

Wild-type UTR of p38 $\alpha$ MAPK containing the putative target of miR-122 was amplified with primers p38 $\alpha$-UTR-F1/p38 $\alpha$ UTR-R1 (Table 1). Mutant UTR (mUTR) with missense mutation of predicted target sites was amplified using the primer p38 $\alpha$-mUTR3-F1/p38 $\alpha$-mUTR3-R1. The two UTR fragments were cloned into the pMIR-REPORT luciferase vector (Ambion, USA), respectively, between the HindIII and Spel restriction enzyme sites. Recombinant plasmids were verified by DNA sequencing (Invitrogen, Guangzhou).

\section{Hoechst 33342 DNA Staining}

FHM cells were stained using fluorescent DNA Hoechst 33342 ( $1 \mu \mathrm{g} / \mathrm{ml}$ in L-15 medium; Sigma-Aldrich, USA) for $5 \mathrm{~min}$, and then washed three times with PBS. The morphology of the nuclei was observed by fluorescence microscopy (Leica, Germany).

\section{Western Blotting}

To obtain the changes of the protein of SGIV MCP, Western blotting was conducted as described previously (Ni et al. 2017). Briefly, cells were lysed using RIPA lysis buffer. The proteins were separated by $10 \%$ SDS-PAGE and transferred to polyvinylidene fluoride (PVDF) membranes. The PVDF membranes were blocked with 5\% dry milk diluted with TBST for $1 \mathrm{~h}$, and then incubated with anti- $\beta$-actin (1:1000 dilution), and anti-SGIV MCP (1:1000 dilution) at $4{ }^{\circ} \mathrm{C}$ overnight. The membranes were washed three times with TBST and incubated with goat anti-rabbit IgG and goat anti-mouse IgG antibodies conjugated with horseradish peroxidase (HPR) at room temperature for $1 \mathrm{~h}$. The membranes were washed five times in TBST and incubated with the SuperSignal West Pico chemiluminescent substrate (Thermo, USA), and then exposed to a chemiluminescence imaging analysis system.

\section{Virus Titer Assay}

To determine the effect of miR-122 on SGIV production, the viral titer was evaluated by TCID $_{50}$ analysis. Cells were transfected with miR-122 mimics $(100 \mathrm{nM})$ and infected with SGIV for $12 \mathrm{~h}$. The cells were collected and freeze-thawed three times at $-80^{\circ} \mathrm{C}$. The cell lysates were then serially diluted and used for GS cell infection in 96-well plates. Approximately 6 days after infection, the viral titer was calculated using $\mathrm{TCID}_{50}$ analysis. 
Table 2 MiR-122 in different species

\begin{tabular}{llll}
\hline miRNA name & Sequence $\left(5^{\prime}-3^{\prime}\right)$ & Species & miRBase number \\
\hline eco-miR-122 & UGGAGUGUGACAAUGGUGUUUG & Epinephelus coioides & Undetermined \\
dre-miR-122 & UGGAGUGUGACAAUGGUGUUUG & Danio rerio & MIMAT0001818 \\
ccr-miR-122 & UGGAGUGUGACAAUGGUGUUU & Cyprinus carpio & MIMAT0026203 \\
hsa-miR-122b-5p & UGGAGUGUGACAAUGGUGUUUG & Homo sapiens & MIMAT0000421 \\
mmu-miR-122b-5p & UGGAGUGUGACAAUGGUGUUUG & Mus musculus & MIMAT0049852 \\
rno-miR-122-5p & UGGAGUGUGACAAUGGUGUUUG & Rattus norvegicus & MIMAT0000827 \\
Bta-miR-122 & UGGAGUGUGACAAUGGUGUUUG & Bos taurus & MIMAT0003849 \\
\hline
\end{tabular}

\section{AP-1 and NF-KB Activation Analysis}

GS cells seeded in 24-well plates were transfected with $100 \mathrm{ng}$ pGL3-luc-NF- $\mathrm{BB}$ reporter plasmid, $50 \mathrm{ng}$ SV40 plasmid, and miR-122 mimics/control miRNA (miR-con) (RiboBio, China) which infected with SGIV. Twentyfour hours posttransfection, the cells were collected. The Renilla luciferase and firefly luciferase activities were measured by the Dual-Luciferase Reporter Assay System (Promega, USA).

\section{Flow Cytometric Analysis of Cell Apoptosis}

To explore the role of miR-122 in SGIV-induced apoptosis, miR-122 mimics or miR-con was transfected into FHM cells seeded in 24-well plates with $2 \mu 1$ of Lipofectamine RNAiMAX (Invitrogen, USA). The cells were collected at $24 \mathrm{~h}$ after SGIV infection, and apoptosis was detected by flow cytometry using the Annexin V-FITC Apoptosis Detection Kit (Becton, Dickinson, and Company, USA). The data acquisition and analysis were performed using a flow cytometer system (Beckman Coulter, USA) and FlowJo VX software.

\section{Caspase-3 Activity Assay}

The activity of intracellular caspase-3 was determined by the caspase fluorescent protease assay kit (BioVision, USA). FHM cells transfected with miR-122 mimics or miR-con were for $24 \mathrm{~h}$ were infected by SGIV. Twentyfour hours later, cells were collected by trypsinization. The reaction was measured on a multi-label plate reader at $405 \mathrm{~nm}$. The activity of caspase-3 was described as the ratio of the absorbance of the treated sample to nitroaniline to the simulated infected cells.

\section{Statistical Analysis}

All the data are expressed as the mean \pm standard error of the mean (SD) and were analyzed with SPSS using one-way analysis of ANOVA followed by Duncan's test. Significance was set at $P<0.05$.

$\mathbf{a}$

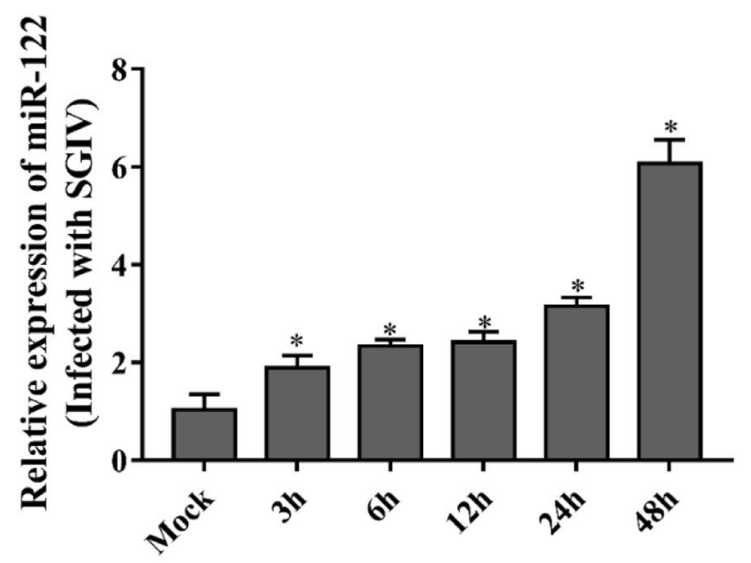

b

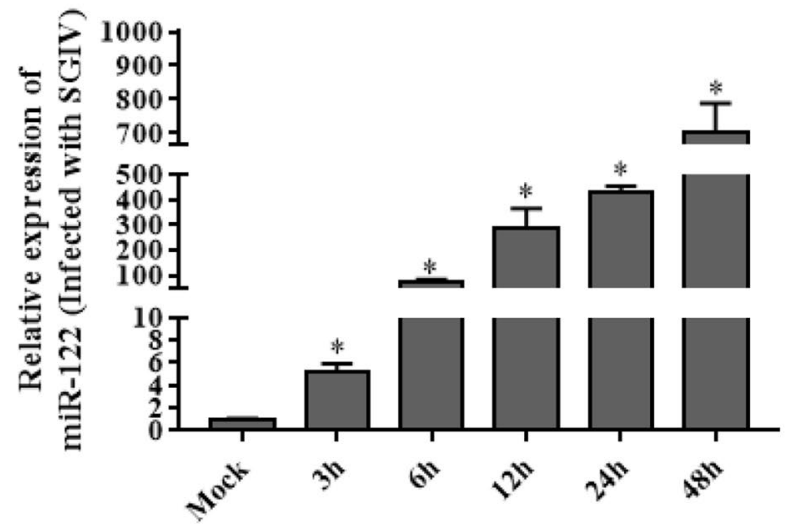

Fig. 1 SGIV infection induced miR-122 expression in GS cells. GS cells in six-well plates were infected with an m.o.i. of 0.1 SGIV. Cells were then collected at $3,6,12,24$, and $48 \mathrm{~h}$, and RNA purified. Levels of miR-122 were determined by real-time PCR and normalized to U6 a or $\beta$-actin b. Significant differences of miR-122 expression between control and SGIV infection group at each time points is indicated with * (significant increase, $P<0.05$ ). All data are expressed as mean $\pm \mathrm{SE}, N=4$ 


\section{Results}

\section{MiR-122 Is Up-regulated by SGIV Infection}

E. coioides miRNAs were obtained by employing the Solexa deep sequencing approach in our lab (Guo et al. 2015). As shown in Table 2, the sequence of $E$. coioides miR-122 was the same as that from the $D$. rerio, $H$. sapiens, $M$. musculus, $R$. norvegicus, and $B$. taurus except $C$. carpio, indicating that miR-122 is highly conserved. To study the relationship between $E$. coioides miR-122 and SGIV infection, the expression pattern of miR-122 during SGIV infection was examined by qPCR. As shown in Fig. 1, the expression of miR122 was up-regulated with a peak at $48 \mathrm{~h}$ during SGIV infection $(P<0.05)$.

\section{The Effect of miR-122 on SGIV Replication}

To test the efficiency of the miR-122 mimics, the expression of miR-122 at 24 and $48 \mathrm{~h}$ was examined after transfection with miR-122 mimics in GS cells. As shown in Fig. 2a, significantly higher expression of miR-122 was detected in cells with the miR-122 mimics for $48 \mathrm{~h}$ $(P<0.05)$, showing that the cells can be used to study the effect of over-expression miR-122.
Twelve hours after transfection with the miR-122 mimics, the cells were infected with SGIV, and then, the SGIV-induced cytopathic effects (CPEs) and the viral gene expression were analyzed at $12 \mathrm{~h}$ postSGIV infection. The results showed that the CPE were significantly increased (Fig. 2b). Moreover, the expression of viral genes (MCP, VP19, ICP18, and LITAF) was significantly up-regulated (Fig. 3a); by western blot, the gray value of SGIV MCP: $\beta$-actin in the cells transfected with miR-122 mimics was 1.36 , and that of the control cells was 1.10 (Fig. 3b), showing that over-expression of miR-122 could enhance the protein synthesis of SGIV MCP. As shown in Fig. 3c, the viral titer, which was used to evaluate viral production, of the miR-122 over-expression cells was significantly higher than that of the control cells $(P<0.05)$.

\section{The Regulatory Effect Between p38a MAPK and miR-122}

According to the analysis of bioinformatics tools, $\mathrm{p} 38 \alpha$ MAPK was the target gene, and the binding energy value was $-22.1 \mathrm{kcal} / \mathrm{mol}$. The miR-122 sequence contains a conserved sequence matching the p38 $\alpha$ MAPK binding 3'-UTR (Fig. 4a). To study the role miR-122 on p38 $\alpha$ MAPK, the p38 $\alpha$ MAPK mRNA was examined in the over-expression miR-122 cells by qPCR. As shown
Fig. 2 MiR-122 promoted the severity of the CPE induced by SGIV infection in GS cells. a The efficiency of miR-122 in the cells after transfection with $100 \mathrm{nM}$ miR-122 mimics (miR-122) or control miR-122 (miR-con). U6 (a) and $\beta$-actin (b) were used as an internal reference and the data was shown as multiples. b Cell morphology of SGIV-infected miRNAtransfected GS cells. At $12 \mathrm{~h}$ after transfection, cells were infected with SGIV at an m.o.i. of 0.1 . After $12 \mathrm{~h}$ of infection, CPE changes (arrows) were observed under microscope, which was characterized by cell rounding and cell aggregation. Significant differences of miR122 expression between control and SGIV infection group at each time points is indicated with * (significant increase, $P<0.05)$. All data are expressed as mean $\pm \mathrm{SD}, N=4$
A

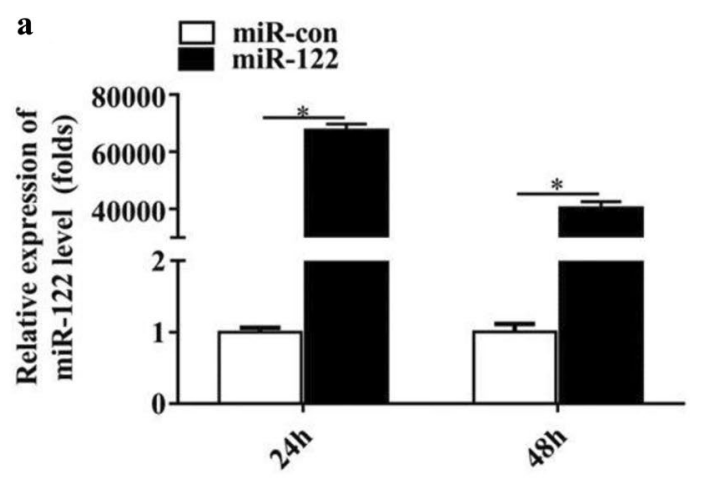

b $\square$ miR-con

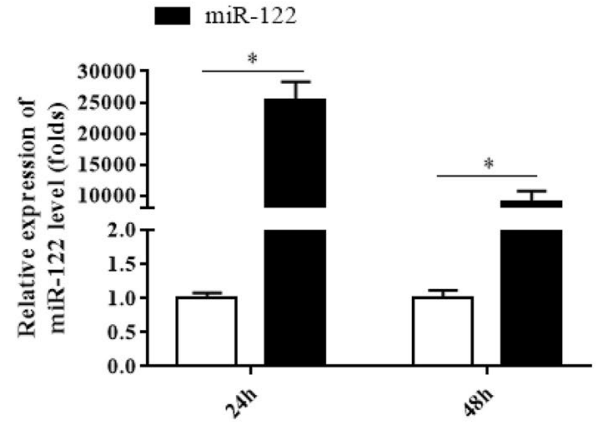

B

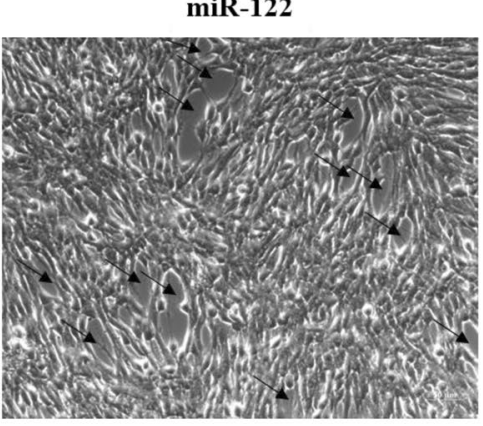

miR-con

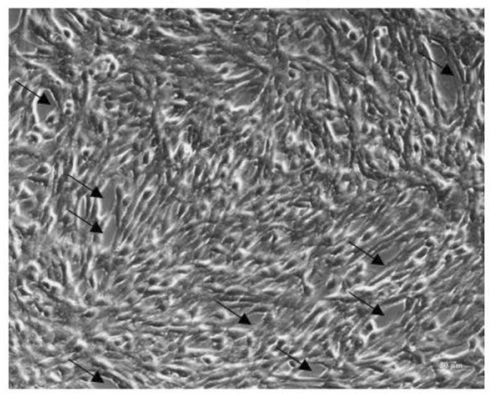


Fig. 3 MiR-122 promoted viral replication and the production of infectious progeny SGIV virions. The GS cells transfected with $100 \mathrm{nM}$ miR-122 mimics (miR-122) or control miR-122 (miR-con) for $12 \mathrm{~h}$ were infected by an m.o.i. of 0.1 SGIV for $12 \mathrm{~h}$. Subsequently, the viral genes, protein levels and viral titres were detected. a The relative expression of four viral genes including MCP, VP19, ICP18, and LITAF were determined by qPCR and normalized to $\beta$-actin (a-1, b-1, $\mathrm{c}-1$, and d-1)or 18S rDNA (a-2, b-2, c-2, and d-2). b The protein levels of SGIV MCP in the cells transfected with miR-122 or miR-con were determined by western blotting, and $\beta$-actin was detected as the internal control. The gray value of SGIV MCP: $\beta$-actin was shown. MCP: SGIV, and actin: $\beta$-actin. $\mathbf{c}$ The viral titers in each group were measured using the $\mathrm{TCID}_{50}$ method. Significant differences of the genes expression between miR-con and miR-122 group is indicated with * (significant increase, $P<0.05)$. All data are expressed as mean $\pm \mathrm{SD}, N=3$
A

a-1

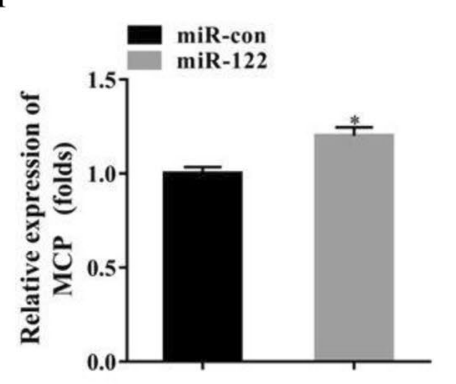

a-2



b-1

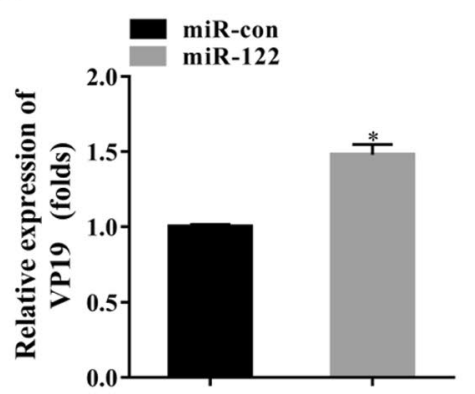

b-2

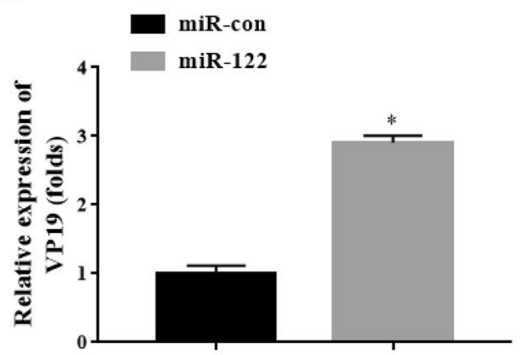

c-1

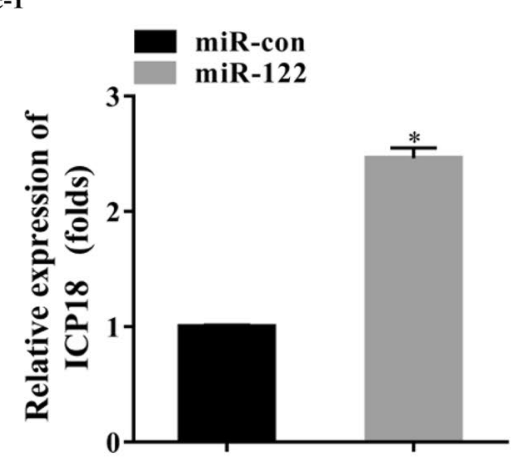

c-2

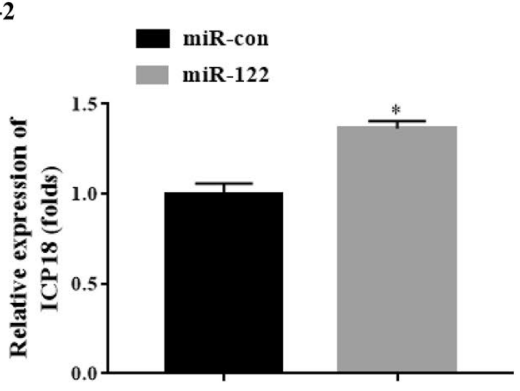

d-1

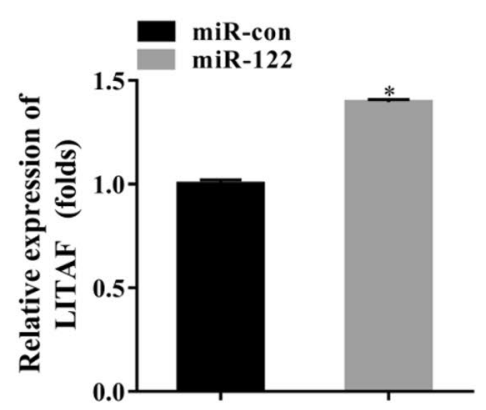

d-2

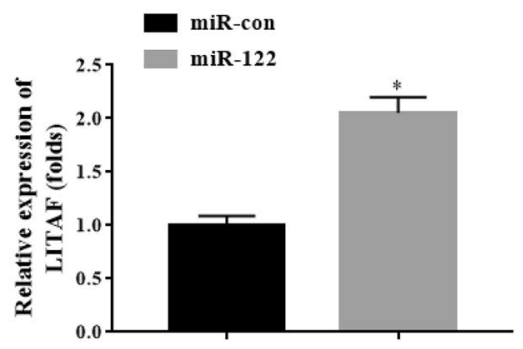

B
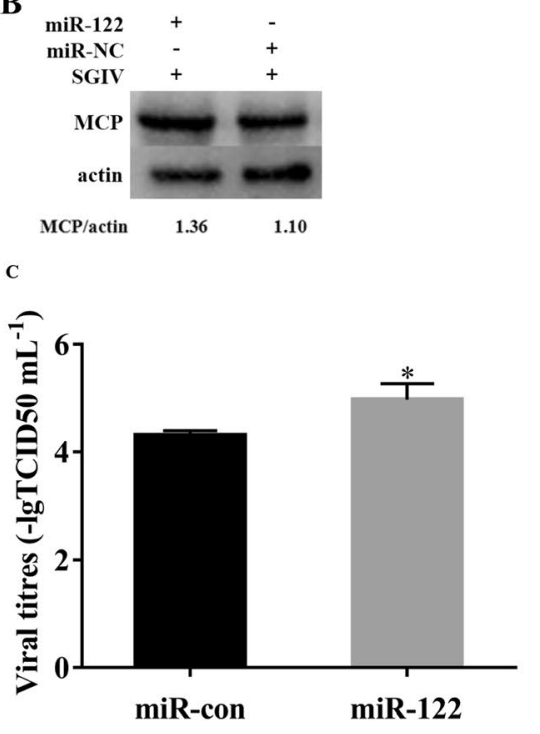
in Fig. 3b, the expression of the p38 $\alpha$ MAPK was significantly down-regulated in the cells transfected with miR-122 mimics $(P<0.05)$. To verify the relationship of p38 $\alpha$ MAPK and miR-122, p38 $\alpha$ MAPK 3 '-UTR or p38 $\alpha$ MAPK mutant $3^{\prime}$-UTR was cloned into a luciferase reporter vector pMIR-REPORT (Ambion, USA), the GS cells transfected with the luciferase reporter containing miR 122 mimics and p38 2 MAPK wild 3'-UTR or p38 $\alpha$ MAPK mutant $3^{\prime}$-UTR was analyzed. As shown in Fig. 3c, luciferase activities were significantly reduced in the cells containing p38 $\alpha$ MAPK wild $3^{\prime}$-UTR $(P>0.05)$, and there is no significant change in the cells of p38 $\alpha$ MAPK mutant 3 '-UTR $(P<0.05)$.

\section{The Effects of miR-122 on Immune Factors}

To verify the roles of miR-122 in immunity, GS cells containing miR-122 mimics or miR-con was infected with SGIV, and the expression of TNF- $\alpha$, IL- 6 , and IL- 8 was determined. The expression levels of TNF- $\alpha$, IL-6, and IL-8 were significantly lower than those in the control group $(P<0.05)$ (Fig. 5), suggesting that miR122 significantly reduced the transcription levels of the immune-related factors.

\section{MiR-122 Inhibits the Activation of AP-1 and NF-KB}

The effect of E. coioides miR-122 on the transcriptional activity of the AP-1 and NF- $\mathrm{KB}$ promoters was been investigated. The GS cells transfected with $100 \mathrm{nM}$ miR122 mimics or control miR-122 at $12 \mathrm{~h}$ were infected by SGIV for $12 \mathrm{~h}$. As shown in Fig. 5, the activation of the AP-1 was significantly reduced $(P<0.05)$, and that of NF- $\mathrm{KB}$ was just slightly down-regulated in the cells transfected with miR-122 mimics for $24 \mathrm{~h}$ compared to the control group $(P>0.05)$ (Fig. 6).

\section{MiR-122 Inhibits SGIV-Induced Cell Apoptosis}

SGIV infection can induce apoptosis in FHM cells (Huang et al. 2011a). To investigate the role of miR122 in SGIV-induced cell apoptosis, the miR-122 mimics/control miR-122 were transfected into FHM cell for $12 \mathrm{~h}$, and then, the cells were infected with SGIV. Cell apoptosis was analyzed at $12 \mathrm{~h}$ after SGIV infection. As shown in Fig. 7a, over-expression of miR122 obviously reduced the SGIV-induced the formation of apoptotic bodies (white arrow); and the expression of the key apoptosis-related factors Bax and p53 was down-regulated (Fig. 7b). The cell apoptosis rate was quantitatively evaluated by performing flow cytometric assays. As shown in Fig. 7c, d, the percentage of early apoptosis in the control cells was $19.17 \%$, and $15.43 \%$ occurred in the cells transfected with miR-122 mimics, indicating that miR-122 can significantly inhibit SGIVinduced cell apoptosis.

\section{The Caspase-3 Activity Detection}

To explore the effect of miR-122 on SGIV-induced caspase activation, the GS cells transfected with miR122 mimics or control miR-122 at $12 \mathrm{~h}$ were infected by SGIV for $12 \mathrm{~h}$, and the activity of caspase- 3 was investigated. As known that SGIV significantly activates caspase-3 activity (Huang et al. 2011b). In this study, the caspase- 3 activity in the cells transfected with miR-122 mimics was slightly down-regulated using the caspase fluorescent protease assay kit $(P>0.05)$ (Fig. 8).

\section{Discussion}

MiR-122 in mammals participates in regulating cell growth, apoptosis, innate immunity, and viral translation, infection, and replication (Jangra et al. 2010; Bandiera et al. 2015; Song et al. 2015; Basu et al. 2014; Jopling 2012; Xu et al. 2019; Haldipur et al. 2018). In this study, the roles of E. coioides miR-122 in SGIV infection and replication, AP-1 and NF- $\mathrm{\kappa B}$ activition, and cell apoptosis were elucidated.

SGIV induced mass mortality in marine fishes, especially in grouper farms. However, the mechanism of SGIV infection needs to be cleared. Many studies have demonstrated the miR-122 in mammals can be involved in the viral infection in higher vertebrates. In this study, miR-122 promoted the replication and proliferation of SGIV, as shown by the significantly enhanced CPE, the up-regulated transcriptional expression levels of virus genes (MCP, VP19, LITAF, and ICP18), and the induced MCP protein levels. In addition, the viral titer was used to evaluate viral production ( $\mathrm{Ni}$ et al. 2017), and miR-122 significantly increased the $\mathrm{TCID}_{50}$, indicating that miR122 promoted the generation of progeny virus. Similar results have been observed in the mammals: miR-122 promoted $\mathrm{HCV}$ virus replication by directly binding to two sites ( $\mathrm{S} 1$ and $\mathrm{S} 2$ ) in the HCV genomic RNA, and at least partially by stimulating IRES-mediated translation (Jangra et al. 2010); miR-122 induced HEV-1 replication by directly interacting with the target site RdRpc (CAC 
$\mathbf{A}$

P38 $\alpha$ UTR

miR-122

5' GAGGCACCUUUUUCUUCCAUCUUUUUGUUUUCCAGGAAACACUCUU \|\|\|\|

3' GUUUGUGGU

1111

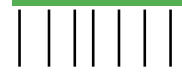

UGUGAGGU

P38 $\alpha$ mUTR

5' GAGGCACCEUUUUCUUCCAUCUUUUUGUUUUCCAGGAAUGUGAGGU

mfe:-22.1 kcal/mol

B

a
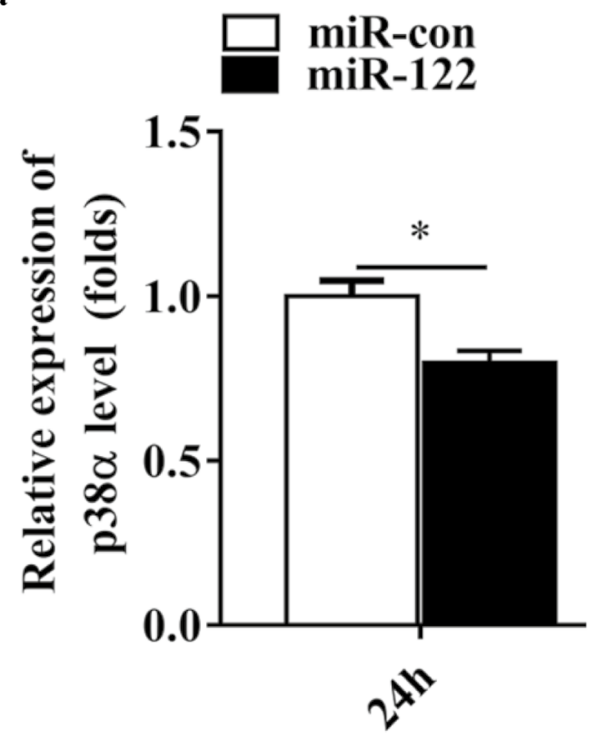

b

$\square$ miR-con

miR-122

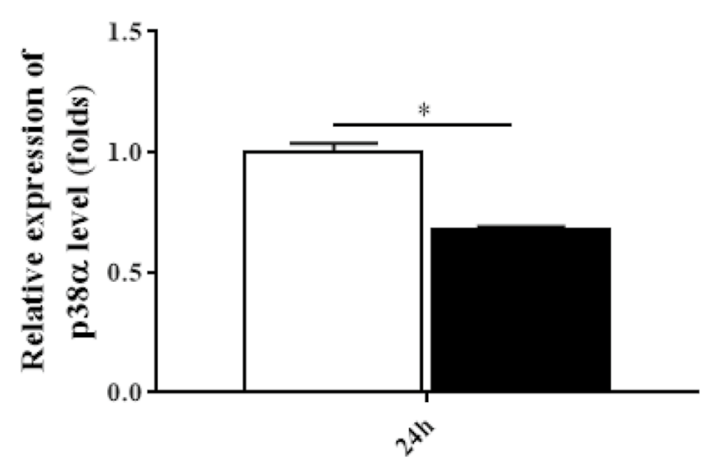

C

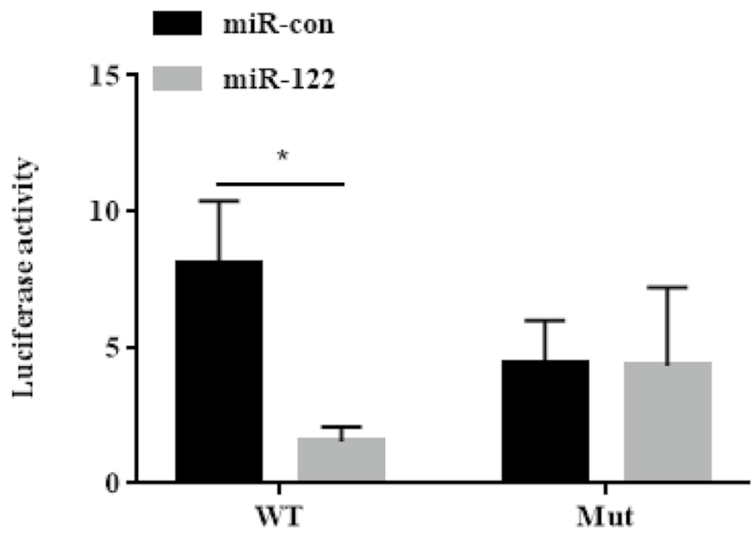


4Fig. 4 miR-122 targeted the $3^{\prime}$ untranslated region (UTR) of $E$. coioides p38 $\alpha$ MAPK. a The predicted sites of the grouper target gene p38 $\alpha$ MAPK and miR-122 and energy threshold. The binding sites were indicated by green shade. $\mathbf{b}$ The expression of p38 $\alpha$ MAPK in the cells transfected with $100 \mathrm{nM}$ miR-122 mimics (miR-122) or control miR-122 (miR-con), and normalized to $\beta$-actin (a)or $18 \mathrm{~S}$ rDNA (b). c The luciferase activity in the cells co-transfected with p38 MAPK (wild or mutant type) and miR-122 mimics. The wild or mutant type UTR of grouper $\mathrm{p} 38 \alpha$ MAPK was cloned into pMIRREPORT luciferase reporter plasmid, and then co-transfected into GS cells with with $100 \mathrm{nM}$ miR-122 mimics (miR-122). The luciferase activity was determined using reporter gene assay. Significant differences of p38 $\alpha$ MAPK expression between miR-con and miR-122 group is indicated with * (significant increase, $P<0.05$ ). All data are expressed as mean $\pm \mathrm{SD}, N=3$

TCC) in the viral genome which provided opportunities for antiviral treatment and management of hepatitis $\mathrm{E}$ (Qian et al. 2010).

SGIV induced the typical apoptosis in FHM cells infected by SGIV, as shown by cellular production of DNA ladders and apoptotic bodies, enhanced caspase activity, and increased mitochondrial membrane potential (Song et al. 2004; Huang et al. 2011a, b, c). Apoptosis is a kind of autonomous cell death in order to maintain the stability of the internal environment and is regulated by genes that are essential for the development and function of cells (Green and Reed 1998). In mammals, the apoptotic pathway can be divided into two categories: the mitochondria-mediated intrinsic apoptotic pathway and the death receptor-mediated intrinsic apoptotic pathway (Green and Reed, 1998; Tiwari et al. 2017; Xiong et al. 2014). Mitochondria release cytochrome $C$, which binds to Apaf-1 and procaspase-9, and then enhances caspase-9 activity, eventually activating downstream factors and causing apoptosis (Tiwari et al. 2017; Reed 2000; Shirjang et al. 2019). The death receptor-mediated internal apoptosis pathway occurs mainly through the TNF receptor family via the transmission of immune signals to cells infected with pathogens, resulting in apoptosis (Elmallah and Micheau 2015; Seol et al. 2015).

In mammals, miRNAs can protect the cells from apoptosis and necrosis by regulating some molecules, endogenous (Bcl-2, Mcl-1), exogenous (TRAIL, Fas, p53), and endoplasmic reticulum stress-induced apoptosis cytokines (Shirjang et al. 2019). miR-122 has been widely reported to participate in the process of apoptosis (Manfe et al. 2012; Guo et al. 2018; Cui et al. 2016). Over-expression miR-122 in bile duct carcinoma cells decreased cell invasion and migration ability, and suppressed cell apoptosis and p53 expression (Wu et al. 2016). MiR-122 mediated by adenoviral vector was a-1

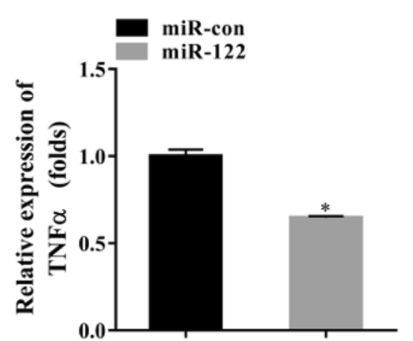

a-2

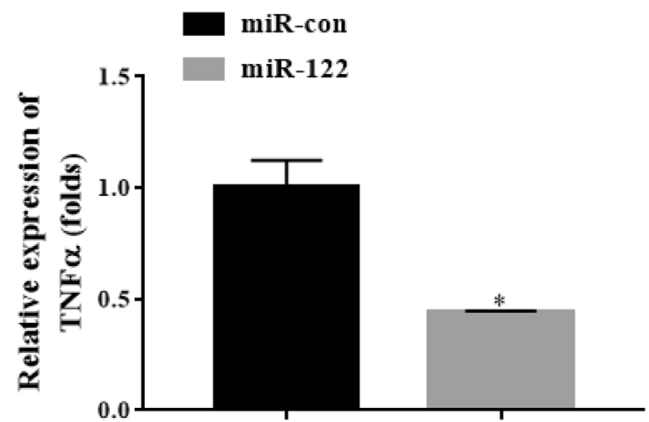

b-1



b-2

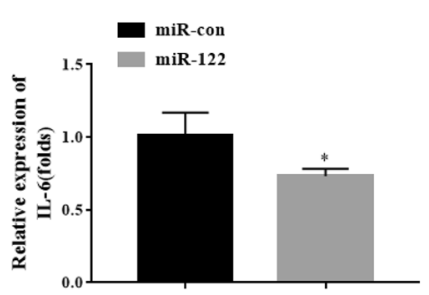

c-1

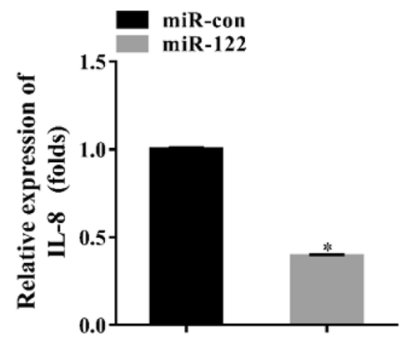

c-2

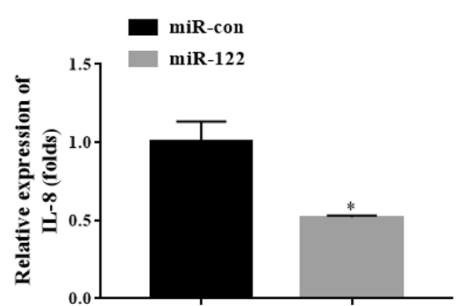

Fig. 5 The effect of miR-122 on the transcription of cellular immune factors, TNF-a, IL-6, and IL-8. The GS cells transfected with $100 \mathrm{nM}$ miR-122 mimics (miR-122) or control miR-122 (miR con) for $12 \mathrm{~h}$ were infected by SGIV for $12 \mathrm{~h}$. Subsequently, the expression genes were detected and normalized to $\beta$-actin (a-1, b-1, c-1) or 18S rDNA (a-2, b-2, c-2). Significant differences of the immune factors expression between miR-con and miR-122 group is indicated with * (significant increase, $P<0.05$ ). All data are expressed as mean $\pm \mathrm{SD}, N=4$ 


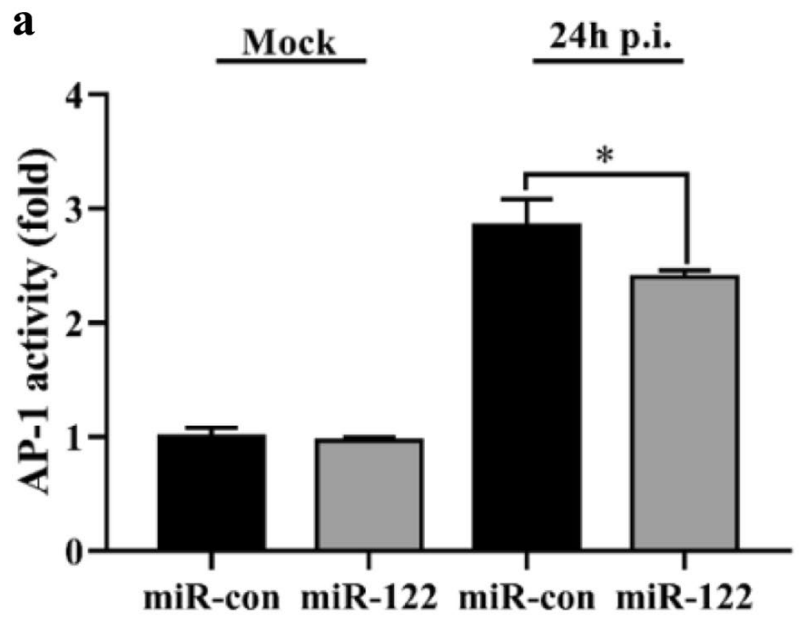

b

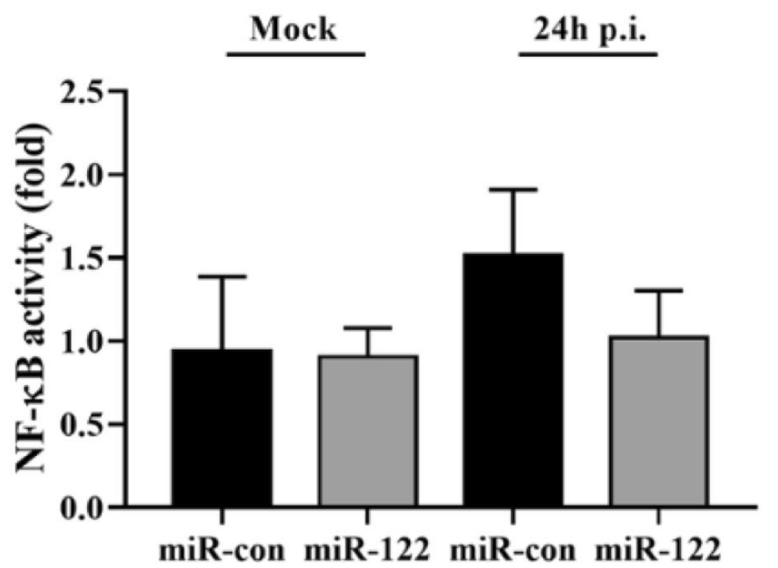

Fig. 6 MiR-122 inhibited AP-1 and NF- $\mathrm{KB}$ activation. The GS cells transfected with $100 \mathrm{nM}$ miR-122 mimics (miR-122) or control miR-122 (miR con) for $24 \mathrm{~h}$ were infected by SGIV for $24 \mathrm{~h}$. Subsequently, the viral genes, protein levels and viral titers were detected. All data are expressed as mean $\pm \mathrm{SD}, N=4$, with SPSS using one-way analysis of ANOVA followed by Duncan's test. $* P<0.05$ compared to control group

induction of apoptosis and cell cycle arrest of cancer cells by inhibiting Bcl-W and CCNG1 expression (Ma et al. 2010). Over-expression of miR-122 significantly reduced N2A cell death, caspase- 3 activity, and increased Bcl-2 protein expression in comparison with miR-NC (Guo et al. 2018). The virus damages the host cell and triggers the host cell apoptosis (Ameisen et al. 2013; Mahalingam et al. 2002). And then, apoptosis can reduce the survival space of the virus to limit the viral proliferation and reinfection (Barber and Host 2001; Ludwig et al. 2006). This study revealed that grouper over-expression miR-122 could reduce the number of apoptosis bodies, apoptosis rates, the expression of proapoptotic genes (Bax and p53), and slightly inhibit the activity of caspase-3.

In this study, p38 $\alpha$ MAPK, one of the important target genes recognized by miR-122, could be mediated by miR-122 during SGIV infection, affects the activity of AP- 1 and NF- $\kappa \mathrm{B}$, and the expression of inflammatory signaling molecules, such as TNF- $\alpha$, IL- 6 , and IL-8. AP-1 and NF- $\mathrm{KB}$ are considered to be involved in immunity and cell apoptosis, and these molecules can also be activated by viral infection (Guo et al. 2016). The production of inflammatory factors is usually caused by NF- $\mathrm{KB}$ and AP-1 (Ahn et al. 2016; Yuan et al. 2018). Studies have reported that miR-122 and the immune response play roles in virus replication. MiR-122 is involved in the regulation of various physiology and biological pathways by regulating target genes and antiviral immunity (Jangra et al. 2010; Jopling 2012; Filipowicz and Grosshans 2011; Li et al. 2012). MiR-122 reduces the inhibitory effect on MDA5 by targeting DAK and regulated the RIG-Ilike receptor signaling pathway to resist viral infection and enhance the immune response in fish (Han et al. 2018). SVCV viral replication is regulated by inhibiting the MAPK and PI3K inflammation-related signaling pathways (Sun et al. 2020). West Nile virus capsid protein and influenza A virus NS1 protein regulate the PI3K pathway, thereby affecting viral replication (Urbanowski and Hobman 2013; Shin et al. 2007).

In summary, the role of grouper miR-122 during SGIV infection was characterized in this study. The expression level of miR-122 was significantly increased during SGIV infection. Over-expression of miR-122 significantly facilitated SGIV replication in grouper cells. MiR-122 suppressed p38 $\alpha$ MAPK-mediated cellular immune response by targeting its $3^{\prime}$ UTR, affect the activities of AP- 1 and NF- $\mathrm{KB}$, the expression of inflammatory factors (TNF- $\alpha$, IL-6, and IL-8) and apoptosis-related genes ( $\mathrm{Bax}$ and p53), and inhibit the SGIV-induced apoptosis. This study provides new insights into understanding the function of fish miRNAs in virus pathogenesis.

Funding This work was funded by the National Natural Science Foundation of China $(31930115,31772877)$, National key research and development plan subject (2019YFD0900801, 2020YFD0901100), foundation of Key Laboratory of Tropical Marine Bio-resources and Ecology, Chinese Academy of Sciences (2019011008), and Hainan Key Laboratory of Tropical Marine Biotechnology (LTMB201902). 
A

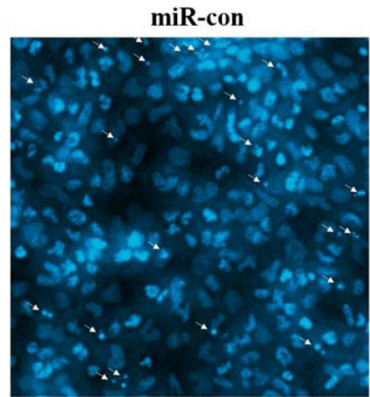

B

a-1

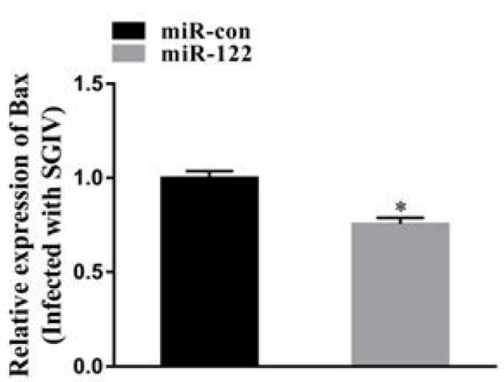

a-2

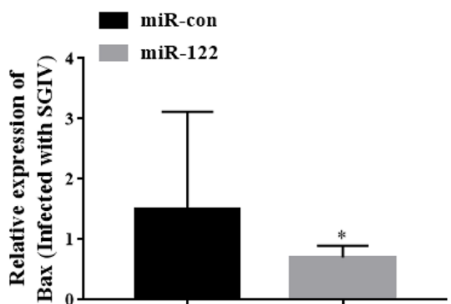

miR-122

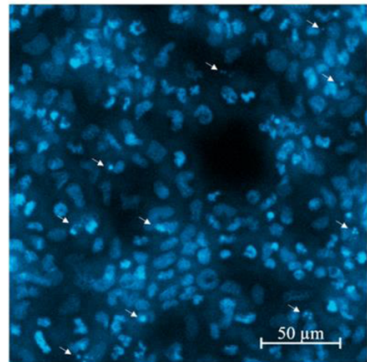

b-1

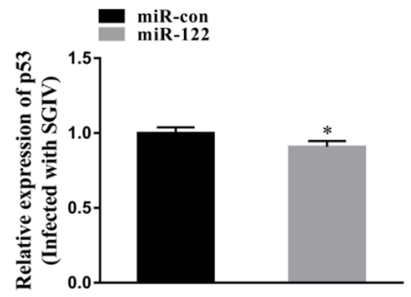

b-2

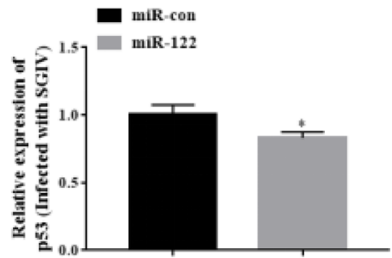

C
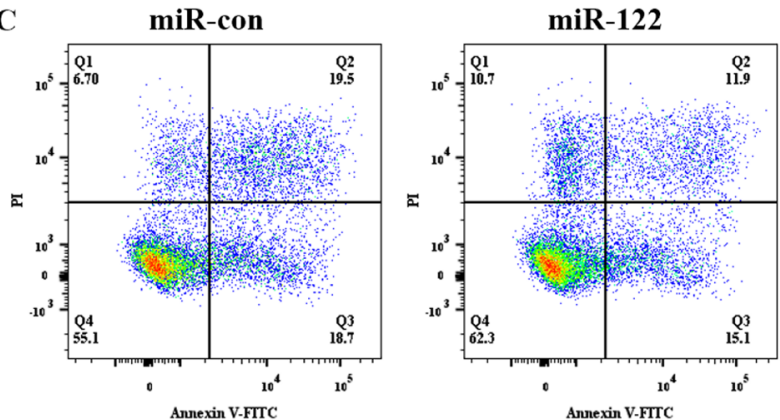

D

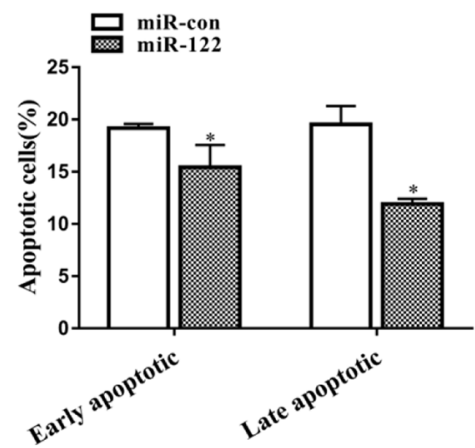

to $\beta$-actin (Bax: a-1; p53: b-1) or 18S rDNA (Bax: a-2; p53: b-2). c Annexin-V+/PI- cells and annexin-V+/PI+ cells are early apoptotic cells and late apoptotic cells, respectively. $\mathbf{d}$ It is based on the average of three parallel experimental data of graph c. Significant differences of the apoptosis between miR-con and miR-122 group is indicated with $*$ (significant increase, $P<0.05$ ). All data are expressed as mean $\pm \mathrm{SD}, N=4$ 




Fig. 8 MiR-122 inhibited the caspase-3 after SGIV infection. GS cells transfected with $100 \mathrm{nM}$ miR-122 mimics (miR-122) or control miR-122 (miR-con) were infected by SGIV for $12 \mathrm{~h}$, and the activity of caspase- 3 was detected by caspase-3 kit. Significant differences of the casepase- 3 activity between miR-con and miR-122 group is indicated with * (significant increase, $P<0.05$ ). All data are expressed as mean $\pm \mathrm{SD}, N=4$

\section{Declarations}

Competing Interests The authors declare that they have no competing interests.

Open Access This article is licensed under a Creative Commons Attribution 4.0 International License, which permits use, sharing, adaptation, distribution and reproduction in any medium or format, as long as you give appropriate credit to the original author(s) and the source, provide a link to the Creative Commons licence, and indicate if changes were made. The images or other third party material in this article are included in the article's Creative Commons licence, unless indicated otherwise in a credit line to the material. If material is not included in the article's Creative Commons licence and your intended use is not permitted by statutory regulation or exceeds the permitted use, you will need to obtain permission directly from the copyright holder. To view a copy of this licence, visit http://creativecommons.org/licenses/by/4.0/.

\section{References}

Ahn SH, Park H, Ahn YH, Kim S, Cho MS, Kang JL, Choi YH (2016) Necrotic cells influence migration and invasion of glioblastoma via NF-kappaB/AP-1-mediated IL-8 regulation. Sci Rep 6:24552

Ameisen JC, Pleskoff O, Lelièvre JD, De Bels F (2013) Subversion of cell survival and cell death: viruses as enemies, tools, teachers and allies. Cell Death Differ 10:S3-S6

Bandiera S, Pfeffer S, Baumert TF, Zeisel MB (2015) miR-122-a key factor and therapeutic target in liver disease. J hepatol 62:448-457

Barber GN (2001) Host defense, viruses and apoptosis. Cell Death Differ 8:113-126
Basu S, Bhattacharyya SN (2014) Insulin-like growth factor-1 prevents miR-122 production in neighbouring cells to curtail its intercellular transfer to ensure proliferation of human hepatoma cells. Nucleic Acids Res 42:7170-7185

Bartel DP (2004) MicroRNAs: genomics, biogenesis, mechanism, and function. Cell 116:281-297

Bushati N, Cohen SM (2007) microRNA functions. Annu Rev Cell Dev Biol 23:175-205

Cui Y, Li H, Gao Z, Liang N, Ma S, Meng F, Li Z, Pan H (2016) Regulation of apoptosis by miR-122 in pterygium via targeting Bcl-w. Invest Ophthalmol Vis Sci 57:3723-3730

Elmallah M, Micheau O (2015) Marine drugs regulating apoptosis induced by tumor necrosis factor-related apoptosis-inducing ligand (TRAIL). Mar Drugs 13:6884-6909

Filipowicz W, Grosshans H (2011) The liver-specific microRNA miR-122: biology and therapeutic potential, Progress in drug research. Prog Drug Res 67:221-238

Fong MY, Zhou W, Liu L, Alontaga AY, Chandra M, Ashby J, Chow A, O'Connor ST, Li S, Chin AR, Somlo G, Palomares M, Li Z, Tremblay JR, Tsuyada A, Sun G, Reid MA, Wu X, Swiderski P, Ren X, Shi Y, Kong M, Zhong W, Chen Y, Wang SE (2015) Breast-cancer-secreted miR-122 reprograms glucose metabolism in premetastatic niche to promote metastasis. Nat Cell Biol 17:183-194

Green DR, Reed JC (1998) Mitochondria and apoptosis. Science 281:1309

Guo C, Cui H, Ni S, Yan Y, Qin Q (2015) Comprehensive identification and profiling of host miRNAs inresponse to Singapore grouper iridovirus (SGIV) infection in grouper (Epinephelus coioides). Dev Comp Immunol 52:226-235

Guo D, Ma J, Li T, Yan L (2018) Up-regulation of miR-122 protects against neuronal cell death in ischemic stroke through the heat shock protein 70-dependent NF-kappaB pathway by targeting FOXO3. Exp Cell Res 369:34-42

Guo M, Wei J, Zhou Y, Qin Q (2016) c-Jun N-terminal kinases 3 (JNK3) from orange-spotted grouper, Epinephelus coioides, inhibiting the replication of Singapore grouper iridovirus (SGIV) and SGIV-induced apoptosis. Dev Comp Immunol 65:169-181

Haldipur B, Bhukya PL, Arankalle V, Lole K (2018) Positive regulation of hepatitis E virus replication by MicroRNA-122. J Virol 92

Han J, Chu Q, Huo R, Xu T (2018) Inducible microRNA-122 modulates RIG-I signaling pathway via targeting DAK in miiuy croaker after poly (I:C) stimulation. Dev Comp Immunol 78:52-60

Hu Y, Du G, Li G, Peng X, Zhang Z, Zhai Y (2019) The miR-122 inhibition alleviates lipid accumulation and inflammation in NAFLD cell model. Arch Physiol Biochem 1-5

Huang X, Huang Y, Ouyang Z, Xu L, Yan Y, Cui H, Han X, Qin Q (2011) Singapore grouper iridovirus, a large DNA virus, induces nonapoptotic cell death by a cell type dependent fashion and evokes ERK signaling. Apoptosis 16:831-845

Huang X, Huang Y, OuYang Z, Cai J, Yan Y, Qin Q (2011) Roles of stress-activated protein kinases in the replication of Singapore grouper iridovirus and regulation of the inflammatory responses in grouper cells. J Gen Virol 92:1292-1301

Huang Y, Yu Y, Yang Y, Yang M, Zhou L, Huang X, Qin Q (2016) Antiviral function of grouper MDA5 against iridovirus and nodavirus. Fish Shellfish Immunol 54:188-196

Huang Y, Huang X, Yan Y, Cai J, Ouyang Z, Cui H, Wang P, Qin Q (2011) Transcriptome analysis of orange-spotted grouper (Epinephelus coioides) spleen in response to Singapore grouper iridovirus. BMC genomics 12:556

Huang Y, Yang M, Yu Y, Yang Y, Zhou L, Huang X, Qin Q (2016) Grouper TRIM13 exerts negative regulation of antiviral 
immune response against nodavirus. Fish Shellfish Immunol 55:106-115

Jangra RK, Yi M, Lemon SM (2010) Regulation of hepatitis C virus translation and infectious virus production by the microRNA miR-122. J Virol 84:6615-6625

Jopling C (2012) Liver-specific microRNA-122: Biogenesis and function. RNA Biol 9:137-142

Lagos-Quintana M, Rauhut R, Yalcin A, Meyer J, Lendeckel W, Tuschl MT (2002) Identification of tissue-specific microRNAs from mouse. Curr Biol 12:735-739

Laudadio I, Manfroid I, Achouri Y, Schmidt D, Wilson MD, Cordi S, Thorrez L, Knoops L, Jacquemin P, Schuit F, Pierreux CE, Odom DT, Peers B, Lemaigre FP (2012) A feedback loop between the liver-enriched transcription factor network and miR-122 controls hepatocyte differentiation. Gastroenterology 142:119-129

Lee RC, Feinbaum RL, Ambros V (1993) The C. elegans heterochronic gene lin-4 encodes small RNAs with antisense complementarity to lin-14. Cell 75:843-854

Li C, Wang Y, Wang S, Wu B, Hao J, Fan H, Ju Y, Ding Y, Chen L, Chu X, Liu W, Ye X, Meng S (2012) Hepatitis B Virus mRNA-Mediated miR-122 inhibition upregulates PTTG1binding protein, which promotes hepatocellular carcinoma tumor growth and cell invasion. J Virol 87:2193-2205

Li Y, Fang Y, Liu Y, Yang X (2015) MicroRNAs in ovarian function and disorders. J Ovarian Res 8:51

Liu N, Chen NY, Cui RX, Li WF, Li Y (2012) Prognostic value of a microRNA signature in nasopharyngeal carcinoma: A microRNA expression analysis. Lancet Oncol 13:633-641

Ludwig S, Pleschka S, Planz O, Wolff T (2006) Ringing the alarm bells: signalling and apoptosis in influenza virus infected cells. Cell Microbiol 8:375-386

Ma L, Liu J, Shen J, Liu L, Wu J, Li W, Luo J, Chen Q, Qian C (2010) Expression of miR-122 mediated by adenoviral vector induces apoptosis and cell cycle arrest of cancer cells. Cancer Biol Ther 9:554-561

Mahalingam S, Meanger J, Foster PS, Lidbury BA (2002) The viral manipulation of the host cellular and immune environments to enhance propagation and survival: A focus on RNA viruses. J Leukocyte Biol 72:429-439

Manfe V, Biskup E, Rosbjerg A, Kamstrup M, Skov AG, Lerche CM, Lauenborg BT, Odum N, Gniadecki R (2012) miR-122 regulates p53/Akt signalling and the chemotherapy-induced apoptosis in cutaneous T-cell lymphoma. PLoS One 7:e29541

Mennigen JA, Panserat S, Larquier M, Plagnes-Juan E, Medale F, Seiliez I, Skiba-Cassy S (2012) Postprandial regulation of hepatic microRNAs predicted to target the insulin pathway in rainbow trout. PLoS One 7:e38604

Mennigen JA, Plagnes-Juan E, Figueredo-Silva CA, Seiliez I, Panserat S, Skiba-Cassy S (2014) Acute endocrine and nutritional co-regulation of the hepatic omy-miRNA-122b and the lipogenic gene fas in rainbow trout, Oncorhynchus mykiss. Comp Biochem Physiol Part B Biochem Mol Biol 169:16-24

Ni S, Yan Y, Cui H, Yu Y, Huang Y, Qin Q (2017) Fish miR-146a promotes Singapore grouper iridovirus infection by regulating cell apoptosis and NF-кB activation. J Gen Virol 98:1489-1499

Pillai RS, Bhattacharyya SN, Filipowicz W (2007) Repression of protein synthesis by miRNAs: How many mechanisms? Trends Cell Biol 17:118-126

Qian J, Zhai A, Kao W, Li Y, Song W, Fu Y, Chen X, Zhang Q, Wu J, Li H, Zhong Z, Ling H, Zhang F (2010) Modulation of miR-122 on persistently Borna disease virus infected human oligodendroglial cells. Antiviral Res 87:249-256
Qiang J, Tao YF, He J, Xu P, Bao JW, Sun YL (2017) miR-122 promotes hepatic antioxidant defense of genetically improved farmed tilapia (GIFT, Oreochromis niloticus) exposed to cadmium by directly targeting a metallothionein gene. Aquat Toxicol 182:39-48

Qin Q, Shi C, Gin KY, Lam TJ (2002) Antigenic characterization of a marine fish iridovirus from grouper, Epinephelus spp. J Virol Methods 106:89-96

Reed JC (2000) Mechanisms of apoptosis. Am J Pathol 157:1415-1430

Shirjang S, Mansoori B, Asghari S, DPHG, Mohammadi A, Gjerstorff M, Baradaran B (2019) MicroRNAs in cancer cell death pathways: apoptosis and necroptosis. Free Radic Biol Med 139:1-15

Seol JY, Mihich E, Berleth ES (2015) TNF Apoptosis Protection Fraction (TAPF) prevents apoptosis induced by TNF, but not by Fas or TRAIL, via NF-кB-induced increase in cFLIP. Cytokine 75:321-329

Shin YK, Liu Q, Tikoo SK, Babiuk LA, Zhou Y (2007) Influenza A virus NS1 protein activates the phosphatidylinositol 3-kinase (PI3K)/Akt pathway by direct interaction with the $\mathrm{p} 85$ subunit of PI3K. J Gen Virol 88:13-28

Song WJ, Qin QW, Qiu J, Huang CH, Wang F, Hew CL (2004) Functional genomics analysis of Singapore grouper iridovirus: complete sequence determination and proteomic analysis. $\mathrm{J}$ Virol 78:12576-12590

Song K, Han C, Dash S, Balart LA, Wu T (2015) MiR-122 in hepatitis $\mathrm{B}$ virus and hepatitis $\mathrm{C}$ virus dual infection. World J Hepatol 7:498-506

Sticht C, De La Torre C, Parveen A, Gretz N (2018) miRWalk: an online resource for prediction of microRNA binding sites. PLoS One 13:e0206239

Su YL, Chen JP, Mo ZQ, Zheng JY, Lv SY, Li PH, Wei YS, Liang YL, Wang SW, Yang M, Dan XM, Huang XH, Huang YH, Qin QW, Sun HY (2019) A novel MKK gene (EcMKK6) in Epinephelus coioides: identification, characterization and its response to Vibrio alginolyticus and SGIV infection. Fish Shellfish Immunol 92:500-507

Sun J, Wang J, Li L, Wu Z, Chen X, Yuan J (2020) ROS induced by spring viraemia of carp virus activate the inflammatory response via the MAPK/AP-1 and PI3K signaling pathways. Fish Shellfish Immunol 101:216-224

Tiwari M, Prasad S, Shrivastav TG, Chaube SK (2017) Calcium signaling during meiotic cell cycle regulation and apoptosis in mammalian oocytes. J Cell Physiol 232:976-981

Urbanowski MD, Hobman TC (2013) The West Nile virus capsid protein blocks apoptosis through a phosphatidylinositol 3-kinase-dependent mechanism. J Virol 87:872-881

Wang B, Wang H, Yang Z (2012) MiR-122 inhibits cell proliferation and tumorigenesis of breast cancer by targeting IGF1R. PLoS One 7:47053-47053

Wu C, Zhang J, Cao X, Yang Q, Xia D (2016) Effect of mir-122 on human cholangiocarcinoma proliferation, invasion, and apoptosis through P53 expression. Med Sci Monitor: Inter Med J Exp Clin Res 22:2685-2690

Xiong S, Mu T, Wang G, Jiang X (2014) Mitochondria-mediated apoptosis in mammals. Protein Cell 5:737-749

$\mathrm{Xu} \mathrm{H}, \mathrm{He}$ JH, Xiao ZD, Zhang QQ, Chen YQ, Zhou H, Qu LH (2010) Liver-enriched transcription factors regulate microRNA-122 that targets CUTL1 during liver development. Hepatology 52:1431-1442

Xu H, Xu SJ, Xie SJ, Zhang Y, Yang JH, Zhang WQ, Zheng MN, Zhou H, Qu LH (2019) MicroRNA-122 supports robust innate immunity in hepatocytes by targeting the RTKs/STAT3 signaling pathway. eLife 8

Yuan M, Meng W, Liao W, Lian S (2018) Andrographolide antagonizes TNF-alpha-Induced IL-8 via inhibition of NADPH Oxidase/ROS/ 
NF-kappaB and Src/MAPKs/AP-1 axis in human colorectal cancer HCT116 Cells. J Agric Food Chem 66:5139-5148

Yurikova OY, Aisina DE, Niyazova RE, Atambayeva SA, Labeit S, Ivashchenko AT (2019) The interaction of miRNA-5p and miRNA$3 p$ with the mRNAs of orthologous genes. Mol Biol 53:692-704
Publisher's Note Springer Nature remains neutral with regard to jurisdictional claims in published maps and institutional affiliations. 